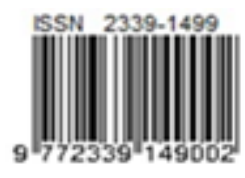

Paper ini telah direview dan dipublikasikan di Jurnal Rekayasa Sistem Industri

Volume 8 No 1 - April 2019

http://journal.unpar.ac.id/index.php/jrsi/index

ISSN 2339-1499 (online)

\title{
Pengendalian Persediaan Produk Obat Herbal pada Permintaan Probabilistik Menggunakan Joint Economic Lot Size
}

\author{
Rainisa Maini Heryanto', Yosi Thedi Setiawan², Vivi Arisandhy ${ }^{3}$ \\ 1,2,3 Program Studi Teknik Industri, Universitas Kristen Maranatha \\ Jl. Prof. drg. Surya Sumantri, M.P.H. No. 65, Bandung \\ Email: rainisa.mh@eng.maranatha.edu, yosithedis@yahoo.com, vivi.arisandhy@eng.maranatha.edu
}

\begin{abstract}
Integration in supply chain is an important factor to consider. Good integration between entity in supply chain can give some advantages from minimize cost to competitiveness between supply chain. Company $X$ is manufacturer of herbs medicine which has single distributor to sell the product. Currently, manufacturer and distributor have their inventory control policies and there is no coordination among echelon. It causes the difference number of production lot from manufacturer and the number of order from distributor, consequently total inventory cost become expensive.

This research will propose Joint Economic Lot Size (JELS) method that can integrate these two echelons and will give the minimum total inventory cost. The proposed JELS method is integration between Cardenas-Barron model about EPQ backorder and Ben-Daya and Hariga model about integration model between single supplier and single consumer. Calculation process begin with forecasting demand, calculation of actual inventory control at echelon manufacturer and distributor, and calculation of proposed method. The result of calculation process show that total actual inventory cost is 5.500.371,476 IDR/month and the proposed method give 4.604.766,665 IDR/month. The proposed method can give saving about $895.604,811$ IDR/month or $16,28 \%$.
\end{abstract}

Key words: cost, integration, JELS, inventory

Abstrak

Integrasi merupakan factor penting untuk diperhatikan dalam sebuah rantai pasok diperhatikan. Integrasi yang baik antar entitas dalam sebuah supply chain dapat memberikan banyak keunggulan baik dari segi biaya yang minimum maupun daya saing antar supply chain. Perusahaan $X$ adalah sebuah manufaktur obat herbal yang mempunyai distributor tunggal untuk memasarkan produknya. Saat ini, manufaktur dan distributor memiliki kebijakan pengendalian persediaan masing-masing dan belum ada koordinasi antar eselon. Hal ini menyebabkan terjadinya perbedaan jumlah lot produksi dari manufaktur dan jumlah pemesanan dari distributor sehingga total biaya persediaan menjadi mahal.

Penelitian ini mengusulkan metode Joint Economic Lot Size (JELS) yang dapat mengintegrasikan kedua eselon dan memberikan total biaya persediaan yang lebih minimum. Model JELS yang diusulkan merupakan penggabungan dari model Cardenas-Barron tentang EPQ backorder dan model Ben-Daya dan Hariga tentang model integrasi pemasok dan pembeli tunggal. Pengolahan data dimulai dari peramalan permintaan, perhitungan pengendalian persediaan aktual pada eselon manufaktur dan distributor, serta perhitungan pengendalian persediaan dengan metode usulan. Hasil pengolahan data menunjukkan total biaya persediaan aktual adalah Rp. 5.500.371,476/bulan dan metode usulan menghasilkan total biaya keseluruhan Rp. 4.604.766,665/bulan. Metode usulan dapat memberikan penghematan sebesar Rp. 895.604.811/bulan atau 16,28\%.

Kata kunci: biaya, integrasi, JELS, persediaan

\section{Pendahuluan}

Pada saat ini, persaingan yang terjadi bukan lagi persaingan antar perusahaan, tetapi persaingan antar supply chain. Dalam sebuah supply chain diperlukan adanya koordinasi dan kolaborasi antar perusahaan karena perusahaan-perusahaan yang berada pada suatu supply chain pada intinya ingin memuaskan konsumen akhir yang sama (Pujawan dan Mahendrawati, 2017). Untuk memenangkan persaingan tersebut, sebuah supply chain harus memiliki strategi dalam melakukan koordinasi, kolaborasi, dan integrasi.

Perusahaan $\mathrm{X}$ adalah sebuah perusahaan manufaktur obat herbal yang dalam 
pendistribusiannya hanya dilakukan oleh sebuah distributor tunggal. Pada saat ini, masing-masing eselon manufaktur dan distributor memiliki kebijakan masing-masing dalam melakukan pengendalian persediaan. Eselon manufaktur akan memproduksi produknya secara massal setiap hari untuk mendapatkan biaya produksi yang ekonomis. Hal ini menyebabkan kondisi gudang pada eselon manufaktur seringkali mengalami penumpukan. Di sisi lain jika permintaan dari eselon distributor sedang tinggi, maka dapat menimbulkan kekurangan pada eselon manufaktur sehingga distributor harus menunggu pesanan di periode yang akan datang (backorder).

Kebijakan persediaan yang dilakukan pada eselon distributor adalah melakukan pemesanan setiap satu minggu sekali dengan jumlah pemesanan yang berubah-ubah sesuai dengan persediaan yang ada dan permintaan dari eselon retailer. Perbedaan karakteristik kebijakan pemesanan dari tiap eselon dan tidak adanya koordinasi, kolaborasi, dan integrasi antar eselon mengakibatkan total biaya yang dikeluarkan oleh masing-masing eselon menjadi besar. Penelitian ini akan mencoba mengusulkan suatu metode yang dapat mengintegrasikan eselon manufaktur dan eselon distributor sehingga dapat menghasilkan total biaya persediaan yang lebih murah dan sebuah supply chain yang lebih kompetitif.

\section{Metode Penelitian}

Tahapan yang dilakukan dalam penelitian ini dapat dilihat pada Gambar 1. Langkah pertama adalah melakukan pengujian kenormalan data permintaan dengan menggunakan $\mathrm{Uji}$ Kolmogorov Smirnov pada SPSS. Pengujian kenormalan ini diperlukan sebagai syarat dari model JELS yang digunakan dalam perhitungan metode usulan. Terdapat nilai $F(k)$, $\mathrm{F}^{\prime}(\mathrm{k})$, dan $\psi(\mathrm{k})$ yang didapatkan dari probabilitas distribusi normal. Jika data mengikuti distribusi normal maka dilanjutkan dengan perhitungan Coefficient of Variation (CV) untuk mengetahui pola data permintaan. Jika data tidak mengikuti distribusi normal, maka harus ditentukan metode pengendalian persediaan lain sesuai dengan distribusi yang diperoleh.

Perhitungan CV menentukan pola data permintaan akan berbentuk stasioner atau non stasioner. Untuk masing-masing pola data terdapat metode yang dapat digunakan untuk melakukan peramalan yang kemudian dipilih metode terbaik berdasarkan nilai error yang paling kecil.

Biaya yang diperhitungkan pada eselon manufaktur terdiri dari biaya setup, biaya simpan, dan biaya kekurangan yang dipenuhi dengan backorder. Sedangkan biaya yang diperhitungkan pada eselon distributor terdiri dari biaya pesan, biaya transportasi, biaya simpan, dan biaya kekurangan yang dipenuhi dengan backorder.

Langkah berikutnya adalah perhitungan total biaya pengendalian persediaan dengan metode yang digunakan manufaktur dan distributor saat ini berdasarkan Tersine (1994) dan langkah terakhir adalah perhitungan total biaya pengendalian persediaan dengan menggunakan metode JELS.

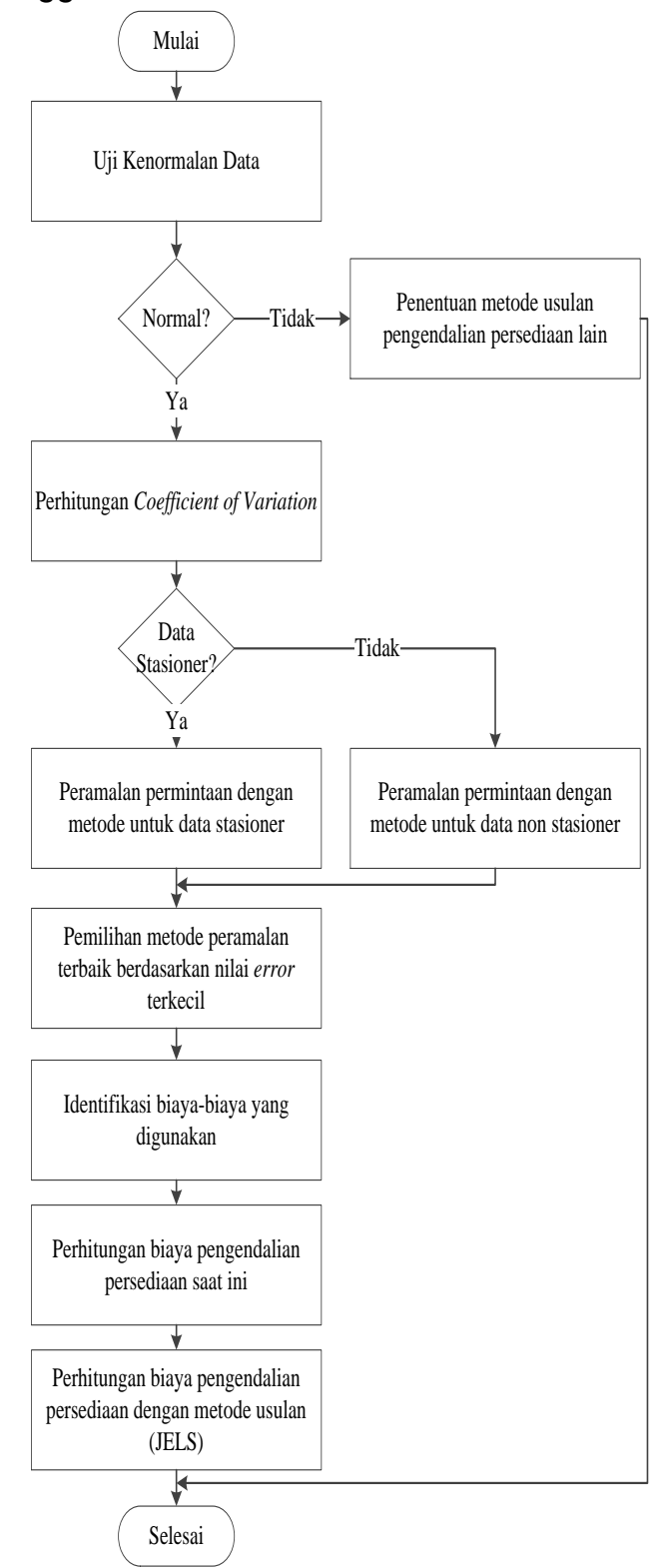

Gambar 1. Tahapan Pengolahan Data 
Penelitian tentang penentuan jumlah produksi yang ekonomis (Economic Production Quanity/EPQ) pertama kali dikembangkan oleh Taft (1918) yang merupakan lanjutan dari model Economic Order Quantity (EOQ). Model $E P Q$ terus mengalami perkembangan dalam beberapa penelitian yang sudah dilakukan. Cardenas-Barron (2001) mengembangkan model EPQ dengan shortage, Pentico, et al (2008) mengembangkan model EPQ deterministik dengan backorder parsial.

Model EPQ biasanya didapatkan dari penurunan total biaya persediaan terhadap jumlah produksi (Q). Model EPQ yang digunakan dalam penelitian ini adalah model Cardenas-Barron (2010) tentang penurunan model persediaan EOQ dan EPQ dengan backorder.

Model ini dipakai sebagai model pada eselon manufaktur dan eselon distributor yang akan diintegrasikan dengan model Ben-Daya dan Hariga (2004) tentang integrasi pemasok dan pembeli tunggal yang lebih dikenal dengan Joint Economic Lot Size (JELS). Dalam penelitian ini dilakukan modifikasi terhadap total biaya dari model Ben-Daya dan Hariga (2004) yang hanya memperhitungkan biaya setup, biaya pesan, biaya simpan, dan biaya transportasi. Modifikasi dilakukan dengan menambahkan biaya backorder pada kedua eselon sesuai dengan kondisi perusahaan saat ini dimana model biaya backorder tersebut diambil dari model Cardenas-Barron (2010) sehingga menghasilkan rumus $Q$ yang baru. Sedangkan algortima perhitungan tetap mengacu pada model Ben-Daya dan Hariga (2004).

Metode JELS dapat mengintegrasikan antara jumlah lot produksi yang dihasilkan oleh eselon manufaktur dan jumlah lot pemesanan yang dilakukan oleh lot distributor. Tujuan dari pengintegrasian yang dilakukan adalah pengurangan biaya-biaya yang tinggi pada perusahaan dan distributor. Algoritma JELS disajikan dalam Gambar 1 berikut ini:

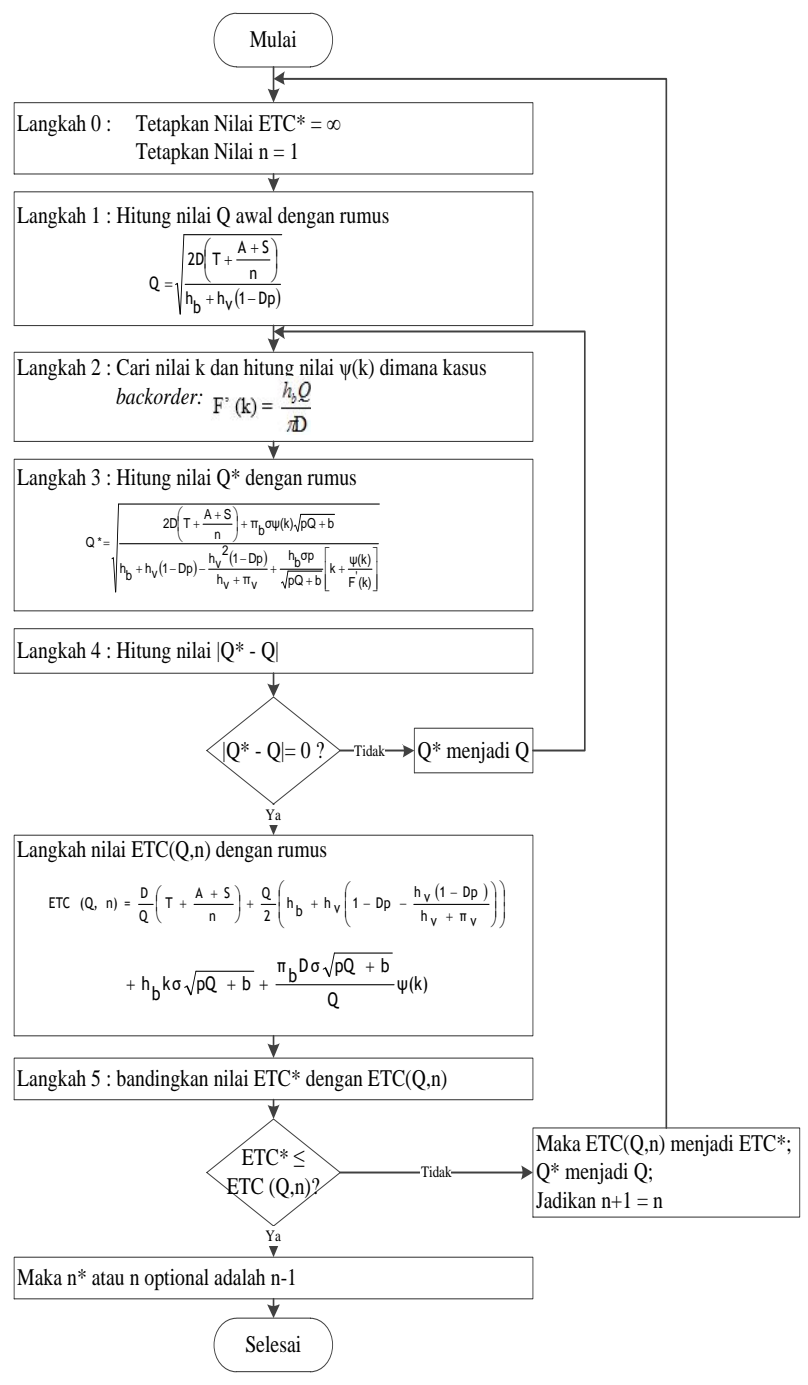

Gambar 2. Algoritma JELS Hasil Pengembangan Keterangan:

$\mathrm{D}=$ Rata-rata permintaan (unit/bulan)

$\sigma=$ Standar deviasi permintaan (unit/bulan)

$\mathrm{P}=$ Kecepatan produksi (unit/bulan)

$\mathrm{p}=$ Kecepatan produksi per unit dalam bulan (bulan/unit)

$\mathrm{n}$ = Jumlah pengiriman dari eselon perusahaan ke eselon distributor (kali/bulan)

$\mathrm{Q}=$ Ukuran lot pengiriman dari eselon perusahaan ke eselon distributor $Q$ (unit/bulan)

$\mathrm{S}$ = Biaya set-up eselon perusahaan (set up/kali)

$\mathrm{A}=$ Biaya pesan eselon distributor dengan ukuran lot pemesanan sebesar $\mathrm{nQ}$ (Rp/pesan)

$\mathrm{T}$ = Biaya kirim untuk eselon distributor dengan ukuran lot pengiriman sebesar $\mathrm{Q}$ (Rp/transportasi)

$\mathrm{B}=$ Backorder level

$h_{v}=$ Biaya simpan eselon perusahaan (Rp/unit/bulan)

$h_{b}=$ Biaya simpan eselon distributor (Rp/unit/bulan) 
$\Pi_{\mathrm{v}}$ = Biaya kekurangan (backorder) eselon (Rp/unit)

$\Pi_{b}=$ Biaya kekurangan persediaan (backorder) eselon distributor (Rp/unit)

$\mathrm{b}=$ Delay time (bulan)

$\mathrm{k}=$ Faktor pengaman atau safety stock

$F^{\prime}(k)=$ Proporsi permintaan tidak dipenuhi dari stock

$\mathrm{F}(\mathrm{k})=$ Tingkat pelayanan (service level)

$$
=1-F^{\prime}(\mathrm{k})
$$

$\psi(\mathrm{k})=$ Partial expectation atau perkiraan kekurangan persediaan parsial

$\mathrm{ETC}=$ Expected total cost atau total biaya gabungan kedua eselon (Rp/bulan)

\section{Hasil dan Pembahasan}

Pengujian kenormalan data permintaan dilakukan dengan taraf nyata $5 \%$ (two tailed) dan didapatkan bahwa data permintaan mengikuti distribusi normal (nilai sig 2 tailed: $0.948>0.025)$. Jumlah data permintaan yang diuji adalah 24 bulan.

Nilai CV yang dihasilkan adalah 0.025 yang menunjukkan bahwa pola data permintaan adalah stasioner sehingga metode peramalan yang digunakan adalah Moving Average (MA), Weighted Moving Average (WMA), Single Exponential Smoothing (SES), Double Exponential Smooting (DES), dan Linear Regression (LR). Metode yang terpilih ditentukan berdasarkan nilai error terkecil. Metode error yang digunakan adalah Mean Absolute Deviation (MAD). Tabel berikut menunjukkan hasil MAD untuk masing-masing metode peramalan. Nilai $\mathrm{N}$ menunjukkan jumlah periode yang diharapkan untuk dipertimbangkan. (Smith, 1989)

Tabel 1. MAD metode peramalan

\begin{tabular}{|c|c|c|}
\hline \multicolumn{2}{|c|}{ Metode Peramalan } & MAD \\
\hline \multirow{3}{*}{ MA } & $\mathrm{N}=1$ & 28.522 \\
\cline { 2 - 3 } & $\mathrm{N}=2$ & 23.395 \\
\cline { 2 - 3 } & $\mathrm{N}=3$ & 18.994 \\
\hline \multirow{3}{*}{ WMA } & $\mathrm{N}=1$ & 28.522 \\
\cline { 2 - 3 } & $\mathrm{N}=2$ & 23.395 \\
\cline { 2 - 3 } & $\mathrm{N}=3$ & 18.994 \\
\hline \multicolumn{2}{|c|}{ SES } & 19.541 \\
\hline \multicolumn{2}{|c|}{ DES } & 18.775 \\
\hline \multicolumn{2}{|c|}{ LR } & $\mathbf{1 6 . 2 2 2}$ \\
\hline \multicolumn{2}{|c|}{ LR }
\end{tabular}

Berdasarkan Tabel 1 di atas, didapatkan bahwa metode yang memiliki nilai MAD terkecil adalah Linear Regression sehingga metode tersebut terpilih untuk meramalkan data permintaan bulan berikutnya yang dapat dilihat pada Tabel 2.
Penelitian ini menggunakan asumsi yang sama dengan model Ben-Daya dan Hariga (2004) dimana pada model tersebut pola permintaan yang deterministik diasumsikan stokastik.

Tabel 2. Hasil peramalan

\begin{tabular}{|c|c|}
\hline Bulan & Hasil Peramalan (strip) \\
\hline 1 & 872.643 \\
\hline 2 & 873.009 \\
\hline 3 & 873.375 \\
\hline 4 & 873.741 \\
\hline 5 & 874.107 \\
\hline 6 & 874.472 \\
\hline 7 & 874.838 \\
\hline 8 & 875.204 \\
\hline 9 & 875.570 \\
\hline 10 & 875.935 \\
\hline 11 & 876.301 \\
\hline 12 & 876.667 \\
\hline Jumlah & 10.490 .862 \\
\hline Rata-rata & 874.656 \\
\hline Std. Dev & $1.318,85$ \\
\hline
\end{tabular}

Pada saat ini, manufaktur menggunakan sistem Economic Production Quantity (EPQ) yaitu produksi secara massal setiap hari untuk mendapatkan biaya produksi yang ekonomis. Sedangkan distributor menggunakan sistem periodik $P(t, E)$, dimana distributor melakukan pemesanan setiap satu minggu sekali dengan jumlah pemesanan yang berubah-ubah sesuai dengan persediaan yang ada dan permintaan dari eselon retailer. Dari hasil perhitungan didapatkan total biaya yang harus dikeluarkan oleh manufaktur adalah Rp. 197.767,246/bulan.

Data yang digunakan untuk perhitungan algoritma JELS dapat dilihat pada Tabel 3.

Tabel 3. Data JELS

\begin{tabular}{|c|c|c|}
\hline Notasi & Besar & Satuan \\
\hline $\mathrm{D}$ & 874.656 & strip/bulan \\
\hline$\sigma$ & $1.318,85$ & strip/bulan \\
\hline $\mathrm{A}$ & 28.656 & $\mathrm{Rp} /$ pesan \\
\hline $\mathrm{P}$ & 892.800 & strip/bulan \\
\hline $\mathrm{p}$ & 0,0000653 & bulan/strip \\
\hline $\mathrm{T}$ & $890.833,33$ & $\mathrm{Rp} /$ transportasi \\
\hline $\mathrm{h}_{\mathrm{v}}$ & 10,206 & $\mathrm{Rp} / \mathrm{strip} / \mathrm{bulan}$ \\
\hline $\mathrm{h}_{\mathrm{b}}$ & 13,060 & $\mathrm{Rp} / \mathrm{strip} / \mathrm{bulan}$ \\
\hline$\Pi_{\mathrm{v}}$ & 520 & $\mathrm{Rp} / \mathrm{strip}$ \\
\hline$\Pi_{\mathrm{b}}$ & 900 & $\mathrm{Rp} / \mathrm{strip}$ \\
\hline $\mathrm{B}$ & 0,042 & bulan \\
\hline $\mathrm{S}$ & $12.543,475$ & Rp/setup \\
\hline $\mathrm{N}$ produksi & 20 & hari/bulan \\
\hline $\mathrm{N}$ & 24 & hari/bulan \\
\hline
\end{tabular}

Data permintaan (rata-rata dan standar deviasi) didapatkan dari hasil peramalan pada tahapan sebelumnya, sedangkan data biaya 
pesan, biaya simpan, biaya setup, dan biaya transportasi didapatkan dengan menjumlahkan elemen-elemen biaya penyusunnya.

Perhitungan dengan metode JELS mengikuti algoritma pada Gambar 2 dengan langkah sebagai berikut:

$\underline{n}=1$

Langkah 0: Tetapkan nilai ETC ${ }^{*}=\infty$ dan $\mathrm{n}=1$

Langkah 1: Hitung nilai Q:

$Q=\sqrt{\frac{2 D\left(T+\frac{A+S}{n}\right)}{h_{b}+h_{v}(1-D p)}}$

$\mathrm{Q}=350.556$ strip/bulan

Langkah 2: Cari nilai $\mathrm{k}$ dan hitung $\psi(\mathrm{k})$

$\mathrm{F}^{\prime}(\mathrm{k})=\frac{h_{b} Q}{\pi_{b} \mathrm{D}}=0,0058$

$\mathrm{F}(\mathrm{k})=1-\mathrm{F}^{\prime}(\mathrm{k})=1-0,0058=0,9942$

$\mathrm{k}=2.53$ dan $\psi(\mathrm{k})=0,0019$

Langkah 3: Hitung nilai $Q^{*}$ :

$Q^{*}=\sqrt{\frac{2 D\left(T+\frac{A+S}{n}\right)+\pi_{b} \sigma \psi(k) \sqrt{p Q+b}}{h_{b}+h_{v}(1-D p)-\frac{h_{v}{ }^{2}(1-D p)}{h_{v}+\pi_{v}}+\frac{h_{b} \sigma p}{\sqrt{p Q+b}}\left[k+\frac{\psi(k)}{F^{\prime}(k)}\right]}}$

$Q^{*}=350.608$ strip/bulan

Langkah 4: Hitung nilai $\left|Q^{*}-Q\right|$

$\left|Q^{*}-Q\right|=0$

$|350.608-350.556|=52 \rightarrow 52>0$

Maka, $Q^{*}$ menjadi $Q=350.608$ dan kembali ke langkah 2.

Iterasi 1:

Langkah 2: Cari nilai k dan hitung $\psi(\mathrm{k})$

$\mathrm{F}^{\prime}(\mathrm{k})=\frac{h_{b} Q}{\pi_{b} \mathrm{D}}=0,0058$

$\mathrm{F}(\mathrm{k})=1-\mathrm{F}^{\prime}(\mathrm{k})=1-0,0058=0,9942$

$k=2,53$ dan $\psi(k)=0,0019$

Langkah 3: Hitung nilai $Q^{*}$

$Q^{*}=350.608$ strip/bulan

Langkah 4: Hitung nilai $\left|Q^{*}-Q\right|$

$\left|Q^{*}-Q\right|=0$

$|350.608-350.608|=0$

Hitung nilai biaya total ekspetasi:

$\operatorname{ETC}(\mathrm{Q}, \mathrm{n})=\frac{\mathrm{D}}{\mathrm{Q}}\left(\mathrm{T}+\frac{\mathrm{A}+\mathrm{S}}{\mathrm{n}}\right)$

$\frac{Q}{2}\left(h_{b}+h_{v}\left(1-D p-\frac{h_{v}(1-D p)}{h_{v}+\pi_{v}}\right)\right)+$

$h_{b} k \sigma \sqrt{p Q+b}+\frac{\pi_{b} D \sigma \sqrt{p Q+b}}{Q} \psi(k)$
$\operatorname{ETC}(Q, n)=\operatorname{Rp~4.682.685,037/bulan~}$

Langkah 5: $\mathrm{ETC}^{*} \geq \operatorname{ETC}(\mathrm{Q}, \mathrm{n})$

$\infty \geq \operatorname{Rp~4.682.685,037}$

Dengan demikian, ETC $(\mathrm{Q}, \mathrm{n})$ menjadi ETC* yaitu $R p$ 4.682.685,037 menjadi ETC*

Maka $n=n+1=1+1=2$ kemudian kembali ke langkah 0 .

Biaya di eselon manufaktur dapat dijabarkan sebagai berikut:

Biaya setup $=\frac{\mathrm{SD}}{\mathrm{nQ}}=$ Rp. 31.292/bulan

Backorder level $(B)=\frac{h_{v} Q(1-D p)}{h_{v}+\pi_{v}}$ $=$ Rp. $137,150 /$ bulan

Biaya simpan $=\frac{\mathrm{h}_{\mathrm{v}}(\mathrm{Q}(1-\mathrm{Dp})-\mathrm{B})^{2}}{2 \mathrm{Q}(1-\mathrm{Dp})}$ $=$ Rp. 34.972,524/bulan

Biaya backorder $=\frac{\pi_{\mathrm{v}} \mathrm{B}^{2}}{2 \mathrm{Q}(1-\mathrm{Dp})}$

$=$ Rp. 686,376/bulan

Biaya di eselon distributor dapat dijabarkan sebagai berikut:

Biaya pesan $=\frac{\mathrm{AD}}{\mathrm{nQ}}=\mathrm{Rp} .71 .488,275 /$ bulan

Biaya transportasi $=\frac{F D}{\mathrm{Q}}$

$$
=\text { Rp. 2.219.224,721/bulan }
$$

Biaya simpan $=h_{b}\left(\frac{Q}{2}+k \sigma \sqrt{p Q+b}\right)$ $=$ Rp. $2 \cdot 318 \cdot 190,638 /$ bulan

Biaya backorder $=\frac{{ }_{\mathrm{b}} \mathrm{D}}{\mathrm{Q}} \sigma \sqrt{\mathrm{pQ}+\mathrm{b}} \psi(\mathrm{k})$

$=$ Rp. 6.830,504/bulan

Perhitungan di atas dilanjutkan ke langkah 0 sampai mencapai total biaya yang paling minimum. Tabel 4 berikut menunjukkan banyaknya iterasi yang menghasilkan total biaya minimum:

Tabel 4. Iterasi Perhitungan dan Total Biaya

\begin{tabular}{|c|c|c|c|}
\hline Iterasi & $\mathbf{Q}$ (strip) & $\begin{array}{c}\mathbf{Q}^{*} \\
\text { (strip) }\end{array}$ & $\begin{array}{c}\text { ETC (Q,n) } \\
\text { (Rp/bulan) }\end{array}$ \\
\hline 1 & 350.556 & 350.608 & $4.682 .685,037$ \\
\hline 2 & 346.660 & 346.712 & $4.630 .885,897$ \\
\hline 3 & 345.352 & 345.404 & $4.613 .489,615$ \\
\hline 4 & 344.696 & 344.747 & $4.604 .766,665$ \\
\hline 5 & 344.548 & 344.600 & $4.623 .314,573$ \\
\hline
\end{tabular}

Dari Tabel 4 di atas dapat dilihat bahwa total biaya paling rendah terdapat pada iterasi 
keempat. Pada Tabel 5 di bawah ini dapat dilihat perincian biaya untuk masing-masing eselon pada kondisi aktual dan dengan menggunakan JELS:

Tabel 5. Biaya Masing-masing Eselon

\begin{tabular}{|c|c|c|}
\hline Eselon & $\begin{array}{c}\text { Metode Aktual } \\
\text { (Rp/bulan) }\end{array}$ & $\begin{array}{c}\text { Metode JELS } \\
\text { (Rp/bulan) }\end{array}$ \\
\hline Manufaktur & $197.767,246$ & $43.018,799$ \\
\hline Distributor & $5.302 .604,230$ & $4.561 .747,866$ \\
\hline Total Biaya & $5.500 .371,476$ & $4.604 .766,665$ \\
\hline
\end{tabular}

Berdasarkan Tabel 5 di atas dapat dilihat bahwa dengan menggunakan metode JELS, terdapat penurunan biaya untuk masingmasing eselon dan total biaya mengalami penurunan sebesar Rp. 895.604,811/bulan atau sebesar $16,28 \% /$ bulan. Kelemahan dari penggunaan metode aktual perusahaan saat ini adalah belum adanya integrasi antar eselon perusahaan dan distributor sehingga masingmasing eselon memiliki ukuran lot masingmasing dan menyebabkan total biaya menjadi meningkat. Pada saat eselon distributor memesan dalam ukuran lot yang sedikit sedangkan eselon manufaktur memproduksi dalam jumlah yang banyak maka akan menyebabkan tingginya biaya simpan pada eselon manufaktur dan sebaliknya apabila eselon distributor memesan dalam ukuran lot yang banyak maka akan menyebabkan biaya tambahan pada eselon manufaktur yaitu biaya backorder.

Tabel 6 berikut ini menunjukkan total masing-masing elemen biaya untuk metode aktual dan metode JELS:

Tabel 6. Komponen Biaya Masing-masing Eselon

\begin{tabular}{|c|c|c|c|}
\hline Eselon & Metode & Komponen Biaya & $\begin{array}{l}\text { Total Biaya } \\
\text { (Rp/bulan) }\end{array}$ \\
\hline \multirow{3}{*}{ Manufaktur } & \multirow{3}{*}{$E P Q$} & Biaya Setup & $12.288,559$ \\
\hline & & Biaya Simpan & $185.129,444$ \\
\hline & & Biaya Backorder & 349.242 \\
\hline \multicolumn{3}{|c|}{ Total Biaya Eselon Manufaktur } & $197.767,246$ \\
\hline \multirow{4}{*}{ Distributor } & \multirow{4}{*}{$P(t, E)$} & Biaya Pesan & $122.988,197$ \\
\hline & & Biaya Transportasi & $3.823 .319,027$ \\
\hline & & Biaya Simpan & $1.355 .153,155$ \\
\hline & & Biaya $\mathrm{Bacl}$ & $1.143,850$ \\
\hline \multicolumn{3}{|c|}{ Total Biaya Eselon Distributor } & $5.302 .604,230$ \\
\hline \multicolumn{3}{|c|}{ Total Biaya Metode Aktual } & $5.500 .371,476$ \\
\hline \multirow{3}{*}{ Manufaktur } & \multirow{3}{*}{ JELS } & Biaya Setup & $7.955,998$ \\
\hline & & Biaya Simpan & $34.387,900$ \\
\hline & & Biaya Backorder & 674,902 \\
\hline \multicolumn{3}{|c|}{ Total Biaya Eselon Manufaktur } & $43.018,799$ \\
\hline \multirow{4}{*}{ Distributor } & \multirow{4}{*}{ JELS } & Biaya Pesan & $18.175,909$ \\
\hline & & Biaya Transportasi & $2.256 .977,566$ \\
\hline & & Biaya Simpan & $2.279 .700,454$ \\
\hline & & Biaya Backorder & $6.893,936$ \\
\hline \multicolumn{3}{|c|}{ Total Biaya Eselon Distributor } & $4.561 .747,866$ \\
\hline \multicolumn{3}{|c|}{ Total Biaya Metode JELS } & $4.604 .766,665$ \\
\hline
\end{tabular}

Berdasarkan Tabel 6 di atas jika dibandingkan dengan metode aktual untuk eselon manufaktur terdapat penurunan biaya setup dan biaya simpan yang sangat signifikan, namun terdapat peningkatan pada biaya backorder. Sedangkan untuk eselon distributor, terdapat penurunan biaya pesan dan biaya transportasi. Namun, terjadi peningkatan pada biaya simpan dan biaya backorder.

Pada beberapa kondisi atau kasus tertentu seringkali terjadi dimana tidak semua eselon mengalami penurunan total biaya walaupun total biaya keseluruhan supply chain mengalami penurunan. Jika terjadi hal demikian maka langkah yang dapat dilakukan adalah pembagian keuntungan (benefit sharing) untuk mencapai win win solution contohnya adalah dengan pemberian potongan harga.

Hal ini menyebabkan JELS tidak dapat diterapkan untuk kondisi dimana antar eselon sulit untuk melakukan koordinasi, kolaborasi, dan integrasi. JELS tidak menjamin bahwa total biaya yang dikeluarkan eselon tersebut menjadi lebih rendah, walaupun secara umum jika dilihat dari total biaya supply chain mengalami penurunan.

\section{Simpulan}

Berdasarkan hasil dan pembahasan dapat disimpulkan bahwa:

a. Kelemahan metode pengendalian persediaan aktual adalah tidak adanya koordinasi yang baik dalam hal jumlah lot produksi perusahaan dan jumlah lot pemesanan distributor karena memiliki kebijakan masing-masing, sehingga menimbulkan total biaya keseluruhan menjadi mahal, yaitu sebesar Rp $5.500 .371,476 /$ bulan.

Hal tersebut disebabkan karena pada eselon distributor terdapat biaya transportasi sebesar $69,150 \%$ dari total biaya keseluruhan karena frekuensi pemesanan dilakukan setiap satu minggu sekali.

b. Metode yang diusulkan dalam penelitian ini adalah Joint Economic Lot Size (JELS). Melalui penerapan metode usulan JELS, maka perusahaan dan distributor akan memiliki jumlah lot yang sudah terintegrasi, sehingga menghasilkan total biaya keseluruhan dalam pengendalian persediaan menjadi lebih kecil dibandingkan menggunakan metode pengendalian persediaan saat ini.

c. Keuntungan yang dapat diperoleh kedua eselon jika menerapkan metode usulan ini adalah menghasilkan total biaya keseluruhan menjadi lebih kecil dibandingkan metode aktual. Hasil perhitungan menggunakan metode JELS akan mendapatkan total biaya keseluruhan 
sebesar Rp 4.604.766,665/bulan dan didapatkan penghematan sebesar $\mathrm{Rp}$. $895.604,811 /$ bulan atau $16.28 \% /$ bulan.

Saran yang dapat diberikan untuk penelitian lanjutan adalah:

a. Jumlah eselon yang diamati tidak hanya eselon manufaktur dan distributor, tetapi dapat juga memperhitungkan eselon retailer dan konsumen.

b. Pertimbangan untuk memperhitungkan produk lain yang diproduksi oleh manufaktur untuk mendapatkan penghematan yang lebih besar.

c. Pertimbangan mengenai kapasitas alat transportasi dalam mengirimkan produk.

\section{Daftar Pustaka}

Ben-Daya, M.; Hariga, M. (2004). No. 92, 75-80. Integrated Single Vendor Model with Stochastic Demand and Variable Lead Time. International Journal of Production Economics.

Cárdenas-Barron, Eduardo,L.,. (2001). 70(3): 289-292. The Economic Production Quantity
(EPQ) with Shortage Derived Algebraically. International Journal of Production Economics.

Cárdenas-Barron, Eduardo, L.,. (2010). No. 59, 948-952. An Easy Method to Derive EOQ and EPQ Inventory Models with Backorders. International Journal of Computers \& Mathematics with Application.

Pentico, D.W. Carl, T., Drake. M.J., (2013). No. 669486. Using a Constant Rate to Approximate a Linearly Changing Rate for $E O Q$ and EPQ with Partial Backordering. Proceedings of the 44th Annual Meeting of the Decision Sciences Institute.

Pujawan, I. N.; Mahendrawati. (2017). Supply Chain Management (Edisi 3). Penerbit Andi.

Taft, E.W. (1918). The Most Economical Production Lot. Iron Age 101.18: 1410-1412.

Tersine, R. J. (1994). Principles of Inventory and Material Management (4 ${ }^{\text {th }}$ Edition), Prentice-Hall International, Inc., USA.

Smith, S.B. (1989). Computer BasedProduction and Inventory Control, PrenticeHall International, Inc., USA. 
Halaman ini sengaja dikosongkan

This page is intentionally left blank 